\title{
Disclosure after large-scale events: the price of honesty?
}

\section{Philip C Hébert}

Correspondence to Dr Philip C Hébert, Family and Community Medicine, Sunnybrook Health Sciences Centre, Room 208a, 2075 Bayview Ave., Toronto M4N 3M5, Canada; philiphebert@utoronto.ca

Accepted 18 March 2015

\section{SLinked}

http://dx.doi.org/10.1136/ bmjqs-2014-003800

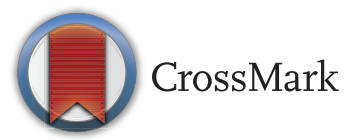

To cite: Hébert PC. BMJ Qual Saf 2015;24:293-294.
Look-backs or investigations into harmful medical events that affect more than one person have become commonplace in medicine. The ethics of disclosing errors to patients in such cases are straightforward and, in many jurisdictions, now mandated by law. Regardless of the ethics, many have understandably worried that disclosure will increase liability exposure. Studies to date have not borne out this concern. ${ }^{12}$ Sometimes, however, an event turns out to affect more than one individual. Such large-scale events may involve improperly sterilised reusable equipment, healthcare providers or patients with potentially transmissible infections, or an impaired or incompetent provider who has committed errors affecting multiple patients over many years.

The ethical arguments for disclosing in the setting of large-scale events are less straightforward than for errors affecting individual patients. Without further testing, the subgroup of patients who have actually suffered an injury cannot be distinguished from the group of patients who have not been harmed. Thus providers must consider the ethical imperative to inform patients of a possible injury but also the reality that the risk is often low. This caveat does not, however, eliminate for many patients the stress that may be caused by the disclosure itself. A framework for guiding disclosure in such circumstances has recently been outlined. ${ }^{3}$ However, the impact of such disclosures on patients' subsequent care-seeking behaviours has not previously been studied.

Wagner $e t a l^{4}$ assess the consequences of large-scale adverse event notifications that were undertaken by five US Veterans Affairs (VA) facilities between 2009 and 2011. The events concerned improperly cleansed endoscopic equipment, inadequate disinfection of colonoscopic equipment, and improper dental infectioncontrol practices.

The VA facilities chosen for this study had very proactive policies of informing patients about possible errors in their care and offering affected patients compensation without litigation. Using administrative data, 9638 cases were identified. Their subsequent medical care was compared with that of 45274 controls for the same time period at the same VA or nearby healthcare facilities.

How did patients respond to the warnings that they may have been exposed inadvertently to hepatitis $\mathrm{C}$ virus (HCV), HIV and hepatitis B virus (HBV)? Not surprisingly, the authors found a robust association between receiving an exposure notification and obtaining testing for HCV, HIV and HBV. The adjusted percentage increase between controls and cases for being tested was $73.2 \%$ for HCV, $72.8 \%$ for HIV and $77.1 \%$ for HBV. However, African-Americans were less likely to be tested for the viruses, with adjusted ORs of 0.74 for HCV, 0.46 for HIV and 0.66 for HBV compared with white patients. Overall, according to the authors, two-thirds of exposed individuals received testing after notificationmeaning that one-third did not do so.

As for returning for the same type of care, the researchers found a decrease in imminent return visits for dental services, although these subsequently rebounded to prenotification levels at 13-18 months. As for switching providers, among veterans over 65 , there was an increased use of VA facilities for certain outpatient services in the first quarter after notification (the authors excluded infectious disease testing) and then a decline in their use. Older patients were more likely to use Medicare providers than VA facilities for outpatient surgery in the year after notification. Limits to the study, as the authors admit, include the lack of knowing the specific patients who were notified, thus having to rely on administrative data for secondary analysis, and the lack of non-VA data for younger patients.

The upshot of this study is twofold. On the one hand, most notified patients 
do get warranted testing carried out in a timely fashion. This is the main reason for notification: to ensure patients potentially harmed by care are assessed and receive proper care. The bad news is that a significant minority do not. The authors do not speculate why one in three notified patients would not seek appropriate testing. Could the notification process be improved? Were the patients tested elsewhere? The only relief here may be that, as we know from most other look-back investigations of modern medicine performed over the past 25 years, few patients are harmed by cases of major lapses in infection control ${ }^{5}$ or by hazards such as providers with transmissible infections. ${ }^{6}$

This is not to suggest we be overly sanguine about infection-control practices or notifications of their breakdown. It does suggest that perhaps we, as patients and providers, need to put these different infection-control practices in perspective. Risks from the handling of reusable medical devices almost certainly pale beside the far greater risks to patient welfare from other routine deficiencies in care-from poor hand hygiene to provider liabilities such as incompetence or lack of skills. Well-known patient safety threats involving medications, diagnosis, surgical procedures and breakdowns in communication and teamwork still deserve greater attention than do the occasional breakdowns in care that affect groups of patients.

On the other hand, this study also reveals that we do not know the best ways to caution groups of patients about deficiencies in their care. It is worrisome, for example, that there are racial differences in the uptake of disclosure by patients when it comes to obtaining appropriate testing, as this study suggests. This disparity is worrisome because, while the threats to patient welfare from inadvertent exposure to infections are very low, they are not zero. Is this lack of testing because African-Americans, already disenchanted with the state of American healthcare, are further alienated from it when notified of potential threats to their well-being? Or is the problem one of perceived access to care?

We do not know the answers to these questions. Understandably, a study of this many patients could not identify and follow-up with individual patients to determine the reasons for their behaviours following disclosure. Some patients and their families are no doubt sceptical about the institutional rationale for disclosure concerning large-scale events. Is it being done to protect patients or is it being done simply to lower medicolegal costs?
There is another unintended consequence of disclosing such events that is sometimes forgotten. Patients, even if not physically harmed, can at times claim psychological harm simply by being informed of the risk of exposure. The claim may be made that they suffered anxiety or were unreasonably stressed once informed they were possibly exposed. The distress, it has been claimed, does not dissipate even though subsequent testing is negative. This argument has not been accepted in Canadian courts ${ }^{7}$-the counter argument being that such psychological stresses are not tantamount to a psychiatric illness, ${ }^{8}$ and, anyway, some stress may be required of citizens if threats to the public welfare are to be addressed.

This study is a reminder that there may be a price to be paid by institutions that warn patients about large-scale adverse events. That they do so is a requirement to preserve patient trust in the healthcare system. But the price of honesty may be patients seeking care elsewhere or-more concerning-not seeking care at all. The other price-that of medicallegal proceedings-is an unfortunate, and perhaps unavoidable, cost of doing business in the modern world.

Twitter Follow Philip Hebert at @ethicsdoc

Competing interests None.

Provenance and peer review Not commissioned; internally peer reviewed.

\section{REFERENCES}

1 Kachalia A, Kaufman SR, Boothman R, et al. Liability claims and costs before and after implementation of a medical error disclosure program. Ann Intern Med 2010;153:213-21.

2 Kraman SS, Hamm G. Risk management: extreme honesty may be the best policy. Ann Intern Med 1999;131:963-7.

3 Dudzinski DM, Hébert PC, Foglia MB, et al. The disclosure dilemma-large-scale adverse events. N Engl J Med 2010;363: 978-86.

4 Wagner T, Taylor T, Cowgill E, et al. Intended and unintended effects of large-scale adverse event disclosure: a controlled before-after analysis of five large-scale notifications. BMJ Qual Saf 2015;24:295-302.

5 Holodniy M, Oda G, Schirmer PL, et al. Results from a large-scale epidemiologic look-back investigation of improperly reprocessed endoscopy equipment. Infect Control Hosp Epidemiol 2012;33:649-56.

6 Danila RN, MacDonald KL, Rhame FS, et al. A look-back investigation of patients of an HIV-infected physician. Public health implications. N Engl J Med 1991;325:1406-11.

7 Healey v. Lakeridge Health Corporation, 2010 ONSC 725 (CanLII).

8 Mustapha v. Culligan of Canada Ltd., [2008] 2 SCR 114, 2008 SCC 27 (CanLII). 